\title{
Clinical and Etiological Profile of Ischemic Stroke in Young Adults: A Prospective, Observational, Hospital based Study from Seacoast Population of South India
}

\begin{abstract}
Kumar NSS*, Padala R, Vallampalli G, Thatikonda A and Prasad PNS

Department of Neurology, Narayana Medical College, Nellore - 524003, India

*Corresponding author: Kumar NSS, Department of Neurology, Narayana Medical College, Nellore - 524003, Andhra Pradesh, India
\end{abstract}

Received: December 17, 2016; Accepted: January 30, 2017; Published: February 01, 2017

\begin{abstract}
Objectives: To evaluate the clinical and etiological profile and outcome of the acute ischemic stroke in young adults in a tertiary-care hospital of south India.

Methods: This study was conducted among 50 acute ischemic stroke patients (clinically and radiologically confirmed) irrespective of sex within the age group of $15-45$ years admitted to Department of Neurology after clearance from Institutional Ethical Committee (IEC). A proforma for each of the acute ischemic stroke patients was maintained where all clinical information in brief including particulars of the subject, chief complaints, past history, proper general physical examination and systemic examinations etc were recorded. The patients had been undergone plain CT (computed tomography) scan/MRI (Magnetic Resonance Imaging) brain at admission for radiological confirmation and to localize the site of lesion in brain. All the included patients were followed upto 3 months of discharge to assess the outcome.
\end{abstract}

Results: Hypertension (56\%) was the most common risk factor among acute ischemic stroke in young adults. Majority of the acute ischemic stroke patients presented with motor weakness ( $94 \%$ - either in the form of hemiparesis or hemiplegia). Stroke of other determined etiology (62\%) with predominant hypercoagulable disorders (Hyperhomocystinemia-55\%) was the most common etiology. Beside, imaging findings confirmed right sided brain lesion in majority of the patients $(60 \%)$ and middle cerebral artery circulation $(80 \%)$ as the most common territory involved in the brain. Most patients had a good functional outcome after 3 months of discharge with NIHSS score of 0-5 in $90 \%$ and mRS score $0-2$ in $92 \%$ patients.

Conclusion: Most common clinical presentation is hemiplegia among the young onset acute ischemic stroke patients. Hypertension is most common risk factor and Stroke of other determined etiology is the most common etiology with middle cerebral arterial circulation being commonly involved and most patients had good functional outcome. Thus, the knowledge of the risk factors, clinical presentation and radiological findings and outcome of acute ischemic stroke in young adults can help in prevention, better understanding of pathogenesis and therapeutic decision making in the disease management.

Keywords: Ischemic stroke; Young adults; Hemiplegia; South india

\section{Introduction}

Stroke is defined by the sudden onset of a neurological deficit due to a focal vascular cause. Acute ischemic stroke, a major subtype of acute stroke, occurs due to loss of blood supply to a part of the brain which initiates ischemic cascade due to free radical production and damage to endothelial lining. The high variability of the clinical presentation of stroke is because of the complex anatomy of the brain and its vasculature [1]. Ischemic stroke in young adults can affect the individuals and indirectly their families, and societies in general, as the patients are affected in the economically productive period of their lives. Almost two thirds of the global burden of acute ischemic stroke is in developing countries [2]. Nearly $10 \%-30 \%$ of all stroke patients in India are within the young adult age group [3-5].
The risk factors of acute ischemic stroke in young adults are more diverse compared to those in the elderly. Proper knowledge of the risk factors of acute ischemic stroke in young patients can prevent the burden of the disease and its recurrences appropriately [6]. The study was conducted to evaluate the risk factors, clinical presentation and outcome of the acute ischemic stroke in young patients in the tertiary care hospital of South India.

\section{Materials and Methods}

This study had been carried out in the Department of Neurology at Narayana medical college, Nellore for a period of $1 \frac{1 / 2}{2}$ year from January 2014 to June 2015. A total of 50 acute ischemic stroke patients (clinically and radiologically confirmed) within the age group of
Austin J Cerebrovasc Dis \& Stroke - Volume 4 Issue 1 - 2017 ISSN : 2381-9103 | www.austinpublishinggroup.com Kumar et al. (C) All rights are reserved
Citation: Kumar NSS, Padala R, Vallampalli G, Thatikonda A and Prasad PNS. Clinical and Etiological Profile of Ischemic Stroke in Young Adults: A Prospective, Observational, Hospital based Study from Seacoast Population of South India. Austin J Cerebrovasc Dis \& Stroke. 2017; 4(1): 1052. 
Table 1: Risk factors of acute ischemic stroke in young adults.

\begin{tabular}{|l|c|c|}
\hline Risk factors $\mathbf{( n = 5 0 )}$ & Frequency $\mathbf{( n = 5 0 )}$ & Percentage (\%) \\
\hline HTN & 28 & $56 \%$ \\
\hline Dyslipidemia & 24 & $48 \%$ \\
\hline Smoking & 22 & $44 \%$ \\
\hline Alcohol & 16 & $32 \%$ \\
\hline Diabetes & 10 & $20 \%$ \\
\hline Valvular Heart disease & 7 & $14 \%$ \\
\hline Atrial fibrillation & 7 & $14 \%$ \\
\hline Anaemia & 6 & $12 \%$ \\
\hline Family history of stroke & 3 & $6 \%$ \\
\hline Severe Left Ventricular (LV) Dysfunction & 2 & $4 \%$ \\
\hline Prosthetic valve & 2 & $4 \%$ \\
\hline Previous history of TIA & 1 & $2 \%$ \\
\hline Coronary artery disease (CAD) & 1 & $2 \%$ \\
\hline
\end{tabular}

Table 2: Clinical presentations of acute ischemic stroke in young adults.

\begin{tabular}{|l|c|c|}
\hline Clinical manifestations & Frequency $\mathbf{( n = 5 0 )}$ & Percentage (\%) \\
\hline Motor weakness & 47 & $94 \%$ \\
\hline Facial palsy & 44 & $88 \%$ \\
\hline Speech disturbances & 36 & $72 \%$ \\
\hline Headache & 23 & $46 \%$ \\
\hline Altered level of consciousness & 19 & $38 \%$ \\
\hline Giddiness & 10 & $20 \%$ \\
\hline Aphasia & 6 & $12 \%$ \\
\hline Vomiting & 6 & $12 \%$ \\
\hline Sensory loss & 5 & $10 \%$ \\
\hline Seizures & 3 & $6 \%$ \\
\hline Visual disturbances & 3 & $6 \%$ \\
\hline Ataxia & 2 & $4 \%$ \\
\hline
\end{tabular}

15-45 years admitted to OPD/Ward/Emergency of Department of Neurology were included irrespective of sex in this study. Exclusion criteria were those patients who refused to take part in the study, head injury, age less than 15 years and more than 45 years, space occupying lesions, subarachnoid hemorrhage, cerebral venous thrombosis, Intracerebral hemorrhage and recurrent cerebrovascular accidents. A pre designed semi-structural proforma, designed for the purpose was used as a study tool. A pro forma for each of the acute ischemic stroke patients was maintained where in a brief clinical information including particulars of the patient, chief complaints, family, personal, dietary history, past history etc were taken. Proper general physical examination and systemic examination were also done and recorded in the pro forma. The acute ischemic stroke patients were subjected to plain CT scan brain or MRI on admission to confirm the diagnosis and also to localize the site of lesion. All the included patients were followed upto 3 months of discharge to assess the outcome of the patients.

This study was conducted after getting approval from Institutional Ethical Committee. Informed consent from the participating individual was also obtained. The data values were entered into MS-
Excel and statistical analysis was done by using IBM SPSS Version 20.0. For categorical variables, the data values were represented as number and percentages.

\section{Results}

The present study is based on the primary data of 50 acute ischemic stroke patients irrespective of sex within the age group of 15-45 years. Majority of the acute ischemic stroke patients were males (76\%). Hypertension (56\%) was the most common risk factor among acute ischemic stroke in young adults, followed by dyslipidemia (48\%), smoking (44\%) and alcohol (32\%) (Table 1). Majority of the acute ischemic stroke patients presented with motor weakness \{either in the form of hemiparesis or hemiplegia\} (94\%) followed by facial palsy (88\%) (Table 2). The most common etiological profile of ischemic stroke in young patients in the present study is stroke of other determined etiology in 31 (62\%) followed by cardioembolism in $8(16 \%)$, stroke of undetermined etiology (due to 2 or more causes) in $5(10 \%)$, large artery atherosclerosis in $4(8 \%)$, and small vessel occlusion 2 (4\%) patients (Table 3). Of the 31 stroke patients of other determined etiology 29 patients had hypercoaguable disorders as an etiological factor, in whom most patients had hyper homocystinemia (Table 3). Beside, imaging findings were present in 30 (60\%) patients on right side of the brain and in $20(40 \%)$ patients on left side. Anterior circulation $(86 \%)$ was the most common territory involved in the brain (Table 4). Most patients at 3 months after discharge had a good functional outcome with an NIHSS score of $0-5$ in $90 \%$ and mRS score of 0-2 in $92 \%$ patients (Table 5). With one patient who had severe disability requiring constant support as the patient underwent decompressive craniotomy because of the malignant MCA infarction, which also resulted in prolonged duration of the hospital stay (mRs 5) and one patient died (mRs 6) during the hospital stay due to the comorbid illness (severe left ventricular dysfunction) and post-stroke complications like aspiration pneumonia and sepsis., despite of the appropriate treatment with antiplatelets, statins, antibiotics and mechanical ventilator support etc.

Table 3: Etiology of ischemic stroke in young patients.

\begin{tabular}{|l|c|c|}
\hline Etiology of ischemic stroke & Frequency (n=50) & Percentage (\%) \\
\hline Stroke of other determined etiology & & \\
\hline Hypercoaguable disorders & 16 & $32 \%$ \\
\hline Hyperhomocystemia & 6 & $12 \%$ \\
\hline Low protein C & 4 & $8 \%$ \\
\hline Low protein S & 2 & $4 \%$ \\
\hline Anti thrombin III & 1 & $2 \%$ \\
\hline APLA & 1 & $3 \%$ \\
\hline & & $3 \%$ \\
\hline & & \\
\hline Dissection (Internal carotid artery) & 8 & $16 \%$ \\
\hline Infectious vasculitis & & \\
\hline (Neurocysticercosis) & 5 & $4 \%$ \\
\hline Cardioembolism & 4 & $10 \%$ \\
\hline Stroke of undetermined etiology & 2 & \\
\hline Large artery atherosclerosis & & \\
\hline Small vessel occlusion & & \\
\hline
\end{tabular}


Table 4: Distribution of acute ischemic stroke in young patients based on the side of the lesion.

\begin{tabular}{|l|c|c|}
\hline \multicolumn{3}{|c|}{ Distribution of the infarct } \\
\hline Side of the lesion & Frequency (n=50) & Percentage (\%) \\
\hline Right side & 30 & $60 \%$ \\
\hline Left side & 20 & $40 \%$ \\
\hline Site of the lesion & & \\
\hline Anterior circulation & 43 & $86 \%$ \\
\hline Posterior circulation & 6 & $12 \%$ \\
\hline Both anterior and posterior circulation & 1 & $2 \%$ \\
\hline
\end{tabular}

Table 5: NIHSS \& mRS scores of young patients with ischemic stroke.

\begin{tabular}{|l|c|c|c|c|c|}
\hline \multirow{2}{*}{} & NIHSS(n=50) & \multicolumn{4}{|c|}{ mRS(n=50) } \\
\cline { 2 - 6 } & $0-5$ & 42901 & $16-42$ & $0-2$ & 42800 \\
\hline Admission & $2(4 \%)$ & $40(80 \%)$ & $8(16 \%)$ & $17(34 \%)$ & $33(66 \%)$ \\
\hline Discharge & $20(40 \%)$ & $26(52 \%)$ & $4(8 \%)$ & $31(62 \%)$ & $19(38 \%)$ \\
\hline 3 months & $45(90 \%)$ & $4(8 \%)$ & $1(2 \%)$ & $46(92 \%)$ & $4(8 \%)$ \\
\hline
\end{tabular}

\section{Discussion}

There is growing evidence for an increase in the incidence of stroke in young adults [7]. In the present study, higher male predominance among the acute ischemic stroke in young adults was observed which may be attributed to a socio cultural bias in india and also males are more exposed to alcohol and smoking. Those patients with alcohol consumption exceeding 14 standard drinks per week or 4 drinks per day were considered as alcoholics, according to the definition by National Institute on Alcohol Abuse and Alcoholism (NIAAA). Similar findings had been reported from studies conducted in western world and in India [8-10]. In this study, hypertension was the most common risk factor of acute ischemic stroke in young adults. Similar finding had been observed in the studies by a group of Indian authors [11-12]. In this study, $48 \%$ of the acute ischemic stroke patients had dyslipidemia which may be attributed to the increasing trends of sedentary lifestyle, smoking, diet pattern and excess alcohol intake and was higher compared to Tan K S, et al. [12]. Smoking is a known risk factor for ischemic stroke. The prevalence of smoking in the present study was $44 \%$ which was higher compared to the previous studies [12-13]. Alcohol is another important contributing risk factor in the development of ischemic stroke. The current study had $32 \%$ patients with a history of excess alcohol intake which was higher compared to the previous studies [12-13]. The current study noticed a prevalence rate of $20 \%$ diabetic patients which was higher compared to the previous Indian studies $[11,13]$. The most common clinical presentation in the current study was motor weakness (94\%) either in the form of hemiparesis or hemiplegia whereas Omkar Prasad Baidya, et al. [13] in their study reported $84 \%$ patients with motor weakness. In comparison to Omkar Prasad Baidya, et al. [13] who had noticed $12 \%$ patients with facial palsy, the current study noticed facial palsy in $88 \%$ patients in whom $86 \%$ had UMN type of facial palsy and $1(2 \%)$ had LMN type of facial palsy.

Out of 50 young ischemic stroke patients in the present study, $62 \%$ patients had stroke of other determined etiology followed by cardio embolism which was seen in $16 \%$. Large artery atherosclerosis was seen in $8 \% .10 \%$ patients had stroke of undetermined etiology with two or more causes and $4 \%$ patients had small vessel occlusion. In comparison, Putaala, et al. [14] in their study on 1008 stroke in young patients aged 15-49 years from Finland, reported stroke of undetermined etiology in 33\% patients and stroke of other determined etiology in $26 \%$. Cardioembolism was found in $19.6 \%$, small artery occlusive disease in $13.8 \%$ and large artery atherosclerosis was seen in $7.5 \%$ patients in their study.

In the current study, out of $62 \%$ patients with stroke of other determined etiology, hypercoaguable disorders were predominantly seen in $94 \%$ patients and $3 \%$ had infectious vasculitis (corpus callosal infarction due to neurocysticercosis). $3 \%$ had right internal carotid artery dissection whereas Dash, et al. [11] a retrospective study which includes of 440 patients, observed that stroke of other determined etiology in $17.3 \%$ patients which was the second common etiology of young onset ischemic stroke in their study. Of those $17.3 \%$ patients with stroke of other determined etiology, dissection was predominantly seen in $51.3 \%$, hyperhomocystinemia in $9.2 \%$, infectious arteritis in $9.2 \%$ and $30.2 \%$ includes all other etiologies like reversible cerebral vasoconstriction syndrome, migraine and plasmacytoma related strokes, elevated lipoprotein A, moya moya disease, cancer, chronic idiopathic thrombocytic thrombocytopenia.

Of all the $94 \%$ patients with hypercoaguable disorders, hyperhomocystenemia (55\%) was predominantly seen followed by Protein S deficiency, Protein C deficiency and antithrombin III deficiency in $21 \%, 14 \%$ and $7 \%$ patients respectively. Antiphospholipid antibody (APLA) was positive in $3 \%$ and in comparison Putaala, et al. [14] in their study reported stroke of other determined etiology [n=262 (26\%)patients] as the second common etiology in their study, noticed hypercoaguable disorders in less than $18 \%$ patients. Increased incidence of hyperhomocysteinemia probably due to higher incidence of smoking, alcoholism in our study. Dietary pattern may also a contributory factor for this finding.

Omkar Prasad Baidya, et al. [13] in their study reported that infarcts on the left side (52\%) of the brain are predominant than right side $(48 \%)$ whereas in the current study, infarcts are more on the right side (60\%) than the left side (40\%). Anterior circulation infarcts $(86 \%)$ were predominantly noticed in the present study which was similar to the findings in Omkar Prasad Baidya, et al. [13] (70\%) and Putaala, et al. [14,15] (52.8\%).

In the current study, of all the 50 patients, most of the patients had good functional outcome after 3 months of discharge and only very slight number of patients had poor outcome.

An NIHSS score of 0-5 was noticed in 90\% patients after 3 months of discharge whom had only mild neurological deficits and is able to manage their daily living activities on their own.

After 3 months of follow up, 92\% had good functional outcome with an mRS score of $0-2$ and only $8 \%$ patients had poor outcome (mRS 3-6) in whom severe disability (mRS 5) was noticed in one patient and death (mRS 6) during the hospital stay was noticed in one patient. The outcome is predominantly determined by the severity of stroke, quality of care provided, rehabilitative measures and risk factor reduction. Hence the outcome may vary between the countries and within the countries and even within same institute/hospital over the time. 


\section{Conclusion}

Incidence of acute ischemic stroke is on rise in young adults and the risk factors are more diverse compared to elder ones. Most common clinical presentation is hemiplegia among the young onset acute ischemic stroke patients. Hypertension is most common risk factor and Stroke of other determined etiology is the most common etiology with middle cerebral arterial circulation been commonly involved and most patients had good functional outcome Thus, the knowledge of the risk factors, clinical presentation and radiological profile of acute ischemic stroke in young patients can help in prevention, better understanding and taking therapeutic decision in management of the disease in this age group. However, the study is limited by small sample size as it is conducted over limited period of time, hence further studies on large sample size can be encouraged.

There were no sources of funding for the conduction of our study.

We thank the faculty and staff members of department of neurology for collecting the data and the patients for their cooperation.

\section{References}

1. Smith WS, English JD, Johnson SC. Cerebrovascular Diseases. In: Fave AS, Bravnald E, Kasper DL, Hsusor SL, Longo DL, Joneson J, et al. editors Harrison's principles of internal medicine.17th ed.USA: McGraw Hills; 2008; 2513-35.

2. Bonita R, Mendis S, Truelsen T, Bogousslavsky J, Toole J, Yatsu F. The global stroke initiative. Lancet Neurol. 2004; 3: 391-393.

3. Kaul S, Bandaru VC, Suvarna A, Boddu DB. Stroke burden and risk factors in developing countries with special reference to India. J Indian Med Assoc. 2009; 107: 358-370.

4. Nagaraja D, Gururaj G, Girish N, Panda S, Roy AK, Sarma GR, et al. Feasibility study of stroke surveillance: data from Bangalore, India. Indian $J$ Med Res. 2009; 130: 396-403.

5. Nencini P, Inzitari D, Baruffi MC, Fratiglioni L, Gagliardi R, Benvenuti L, et al. Incidence of stroke in young adults in Florence, Italy. Stroke. 1988; 19 977-998
6. Adams HPJ, Bendixen BH, Kappelle LJ, Biller J, Love BB, Gordon DL, et al. Classification of subtype of acute ischemic stroke: definitions for use in a multicenter clinical trial. Stroke. 1993; 24: 35-41.

7. George MG, Tong X, Kuklina EV, Kuklina EV, Labarthe DR. Trends in stroke hospitalizations and associated risk factors among children and young adults, 1995-2008. Ann Neurol. 2011; 70: 713-721.

8. Ji R, Schwamm LH, Pervez MA, Singhal AB. Ischemic stroke and transient ischemic attack in young adults: risk factors, diagnostic yield, neuroimaging, and thrombolysis. JAMA Neurol. 2013; 70: 51-57.

9. Nayak SD, Nair M, Radhakrishnan K, Sarma PS. Ischemic stroke in the young adult: clinical features, risk factors and outcome. Natl Med J India. 1997; 10:107-112.

10. Lipska K, Sylaja PN, Sarma PS, Thankappan KR, Kutty VR, Vasan RS, et al. Risk factors for acute ischaemic stroke in young adults in South India. J Neurol Neurosurg Psychiatry. 2007; 78: 959-963.

11. Dash D, Bhashin A, Pandit AK, Tripathi M, Bhatia R, Prasad K, et al. Risk Factors and Etiologies of Ischemic Strokes in Young Patients: A Tertiary Hospital Study in North India. J Stroke. 2014; 16: 173-177.

12. Tan KS, Navarro JC, Wong KS, Huang YN, Chiu HC, Poungvarin N, et al Clinical profile, risk factors and aetiology of young ischaemic stroke patients in Asia: A prospective, multicentre, observational, hospital- based study in eight cities. Neurology Asia. 2014; 19: 117-127.

13. Prasad BO, Sunita T, Kauser U. Acute ischemic stroke in young adults-a hospital based study in North India. International Journal of Biomedical Research. 2015; 6: 113-117.

14. Putaala J, Metso AJ, Metso TM, Konkola N, Kraemer Y, Haapaniemi E, et al Analysis of 1008 consecutive patients aged 15 to 49 with first ever ischemic stroke: the Helsinki young stroke registry. Stroke. 2009; 40: 1195-1203.

15. Putaala J, Strbian D, Mustanoja S, Haapaniemi E, Kaste M, Tatlisumak T. Functional outcome in young adult ischemic stroke: impact of lipoproteins. Acta Neurol Sc and 2013; 127: 61-69.
Austin J Cerebrovasc Dis \& Stroke - Volume 4 Issue 1 - 2017 ISSN : 2381-9103 | www.austinpublishing group.com Kumar et al. (C) All rights are reserved
Citation: Kumar NSS, Padala R, Vallampalli G, Thatikonda A and Prasad PNS. Clinical and Etiological Profile of Ischemic Stroke in Young Adults: A Prospective, Observational, Hospital based Study from Seacoast Population of South India. Austin J Cerebrovasc Dis \& Stroke. 2017; 4(1): 1052 